\title{
GÉNERO E PRECARIEDADE PROFISSIONAL: O CASO DAS LICENCIDAS DA Universidade do Porto
}

\author{
Isabel Dias \\ mdias@letras.up.pt \\ Universidade do Porto
}

Luísa Veloso

luisa.veloso@iscte.pt

Centro de Investigação e Estudos de Sociologia

Recibido: 27-02-09

Aceptado: 09-03-09

\section{Resumo}

$\mathrm{O}$ artigo tem como objectivo analisar as relações entre trabalho e género. Tomando como ponto de partida um estudo sobre a precariedade de um conjunto de licenciados/as da Universidade do Porto, propõe-se um enfoque sobre algumas das entrevistas realizadas, cuja análise de cariz compreensivo permitiu traçar "retratos" de precariedade. Tais retratos encontram-se organizados por tipo de trajectória profissional. Conferindo destaque aos discursos das entrevistadas, apresenta-se uma análise num registo co-autoral, cruzando-se o discurso na primeira pessoa das entrevistadas, com as interpretações das autoras. A leitura dos discursos das entrevistadas permite estruturar as especificidades associadas à relação entre trabalho e género.

Palavras-chave: Género; precariedade profissional; licenciatura, ensino superior, mercado de trabalho. 


\title{
Resumen:
}

El artículo tiene como objetivo analizar las relaciones entre trabajo y género. Tomando como punto de partida un estudio sobre la precariedad de un conjunto de licenciados/as de la Universidad de Oporto, se propone un enfoque sobre algunas entrevistas realizadas cuyo análisis de carácter comprensivo permitió trazar "retratos" de precariedad. Dichos retratos se encuentran organizados por tipo de trayectoria profesional. Poniendo de relieve los discursos de las entrevistas, se presenta un análisis en un registro coautoral, cruzándose el discurso en primera persona de las entrevistadas con las interpretaciones de las autoras. La lectura de los discursos de las entrevistadas permite estructurar las especificidades asociadas a la relación trabajo y género.

Palabras clave: género, precariedad profesional, licenciatura, enseñanza universitaria, mercado laboral.

\begin{abstract}
:
The article aims to examine the relationship between labor and gender. Taking as starting point a study about the precariousness of the graduates of the University of Porto, it proposes a focus on some of the interviews, which enabled to develop a comprehensive analysis and to trace a set of "portraits" of precariousness. These pictures are presented by type of professional track record. Giving prominence to the words of the interviewees, the analysis adopts a co-author perspective, crossing up the speech in first person from the interviewed with the interpretations of the authors. The reading of the interviews allows the understanding of the relationship between work and gender.
\end{abstract}

Key-words: gender, professional precariousness, graduation, college education, labour market. 


\section{Introdução}

$\mathrm{O}$ artigo tem por base alguns dos resultados de um projecto de investigação que reflecte sobre a precariedade profissional dos/as licenciados/as da Universidade do Porto em ciências sociais, humanidades e administração entre os anos lectivos de 1996/97 e 2003/04 ${ }^{1}$. Visa dar a conhecer os processos de transição para o trabalho dos/as licenciados/as, as suas trajectórias de precariedade e as relações desta com o género e a vida familiar e social. Neste artigo, a análise incide, em particular, sobre as articulações entre trabalho (precário) e relações sociais de género.

Atendendo aos objectivos referidos, as trajectórias profissionais e o género emergem como duas dimensões centrais do presente artigo. As primeiras são entendidas como conjuntos de acontecimentos profissionais que marcam o percurso do indivíduo, adquirindo sentido por relação aos movimentos que estruturam o mercado de trabalho (Paul in Coutrot; Dubar, dir., 1992: 146). O género é entendido como a elaboração cultural do sexo. Refere-se aos comportamentos e expectativas socialmente aprendidos a propósito de ambos os sexos (Andersen, 1997). Constitui uma categoria social que estabelece as nossas possibilidades de vida e orienta as relações sociais. Remete-nos para a interiorização por homens e mulheres dos efeitos das atribuições sociais aos comportamentos que se esperam e exprimem em todos os domínios da vida social (Guionnet e Neveu, 2005: 5). A introdução do conceito de género não só nos permite contrariar o argumento biológico enquanto base de sustentação da segregação dos papéis sexuais, como nos proporciona uma lente de leitura importante das vivências de precariedade por parte da nossa população. Constitui um princípio basilar de organização e diferenciação social, mas também de construção de determinadas visões do mundo (Aboim, 2007: 35; Dias, 2008: 155).

\footnotetext{
${ }^{1}$ Para um maior desenvolvimento acerca dos objectivos e dimensões do estudo, assim como da estratégia metodológica accionada e dos instrumentos de recolha de informação construídos, v. GONÇALVES, coord. (2009).
} 
Do ponto de vista metodológico, o estudo contemplou a administração de um inquérito por questionário on line (tendo sido obtido um total de 921 respostas, o que corresponde a uma taxa de resposta de $27,4 \%$ ) e a realização de 32 entrevistas em dois momentos temporalmente distintos (cerca de sete meses) no sentido de abranger as mudanças vividas pelos/as licenciados/as nas suas trajectórias profissionais. Foi realizada uma análise multivariada, a qual permitiu a constituição de um conjunto de tipos de trajectórias profissionais, agrupados em trajectórias profissionais precárias e não precárias. Na medida em que o estudo versou a problemática da precariedade, a selecção dos indivíduos a entrevistar teve por base os tipos de trajectórias profissionais precárias, cruzando com outros critérios, tais como o estado civil, a detenção, ou não, de filhos e a área de formação académica (Línguas e Literaturas Modernas, Psicologia, Sociologia, Geografia, Economia, Gestão, Arqueologia, História, História de Arte e Filosofia).

As entrevistas foram alvo de uma análise qualitativa, com recurso ao software NVivo7. Procedeu-se a uma análise categorial das mesmas com vista à construção de um conjunto de retratos de precariedade dos 32 entrevistados. Destes, 27 são mulheres. Tal representatividade, a par do focus analítico supra apresentado deste artigo - relação entre trabalho (precário) e género - conduziu-nos a seleccionar, selectivamente, dois retratos femininos de precariedade por tipo de trajectória profissional.

Perspectiva-se, desta forma, dar a conhecer, por um lado, o género da precariedade profissional dos licenciados da Universidade do Porto; e, por outro, como a organização da vida familiar e profissional se constrói com base nas assimetrias de género.

\section{Género e vida profissional: algumas reflexões teóricas}

O género é um conceito fundamental para a análise do lugar das mulheres no âmbito da divisão social do trabalho. Através dele é possível a apreensão das relações 
hierárquicas entre os sexos e dos processos de discriminação e desigualdade no trabalho.

Enquanto elaboração cultural, corresponde ao reconhecimento, por parte das diversas disciplinas científicas, do declínio do masculino neutro e universal. Os paradigmas clássicos (positivista e funcionalista), assentes no argumento da natureza, isto é, do destino biológico dos indivíduos, resistiram profundamente à introdução desta nova forma de pensar as relações sociais entre os sexos (Bourdieu, 1998). Tais paradigmas legitimaram, por exemplo, a noção de "carreira feminina". Esta, quando muito, deveria ser compatível com a vida familiar e desenvolvida em sectores de actividade associados ao "modo de ser feminino" (Amâncio, 1994: 27).

As diferenças de género na análise da relação entre trabalho e vida familiar têm sido largamente estudadas principalmente pelas correntes feministas. $\mathrm{O}$ feminismo liberal e socialista, por exemplo, reclamam que é necessário observar, quer a esfera laboral, quer a familiar, para se compreender a desigualdade sexual inerente aos processos socioeconómicos. A referida corrente aplica o conceito de género para interpretar as desigualdades entre homens e mulheres no espaço público e privado. Por seu turno, o feminismo socialista usa-o com vista a explicar os processos complexos de produção e reprodução das assimetrias. O enfoque de género também nos conduz a olhar a interacção entre família e trabalho em termos de conflito. Neste caso, tem-se em consideração, por um lado, as relações de género que se estabelecem dentro dos sistemas sociais, que são também relações de poder; e, por outro, a vivência das relações entre família e trabalho como domínios contraditórios ou incompatíveis. Tal incompatibilidade pode conduzir os indivíduos, em particular as mulheres activas, a viverem em tensão permanente estes dois domínios - trabalho e família - uma vez que, não só estão mais expostas às imposições de género, como sentem que o tempo que lhes resta para dedicar à família é insuficiente (Gálvez e Linares, 2005: 151). O peso da esfera familiar para as mulheres traduz-se num enorme stress, devido às tensões vividas em matéria de afectação do tempo para o trabalho e do tempo para a família. Este conflito conduz muitas mulheres a abdicar de alguns dos seus projectos pessoais, 
profissionais ou familiares (Crompton, 2006). Assim, as que optam por uma profissão a tempo inteiro, ora saem fragilizadas no seu processo de autonomização pelo trabalho, ora as suas trajectórias profissionais são desvalorizadas, de tal forma que as adiam para uma fase ulterior e reorientam as suas perspectivas de vida a favor da conjugalidade e da maternidade (Gavray, 2006: 63).

Tais cenários ocorrem no âmbito de uma divisão social do trabalho em que a esfera familiar está adscrita a um só género. A existência de uma organização familiar em que a prestação de cuidados continua a ser uma responsabilidade feminina, não só constitui um obstáculo à promoção da paridade entre os sexos, como não permite uma diversificação progressiva das esferas de realização dos trabalhadores masculinos, privados ao longo da história das funções expressivas junto dos filhos (Gavray, 2006; Dias, 2007).

As desigualdades com base no género persistem entre as gerações mais jovens e, por vezes, assumem formas renovadas. Gavray (2006: 62) refere que embora o peso da esfera familiar sobre a profissional se faça sentir para ambos os sexos, ele exerce-se de forma oposta e permanece condicionado ao contexto de emprego em que homens e mulheres se situam. Com base nas suas pesquisas, a autora refere que o mercado de trabalho, em recomposição, se apoia sobre normas "sexuadas" tradicionais, em detrimento das carreiras profissionais de uma boa parte das mulheres jovens. A impulsão dada à trajectória de emprego feminino, na fase inicial, pelo diploma escolar, tende a recuar quando pressões exteriores e familiares se tornam mais precisas.

A procura de áreas de formação e consequentemente de profissões que permitem, de alguma forma, um maior equilíbrio entre investimento profissional e vida familiar, tem-se observado sobretudo ao nível da inserção das mulheres em "lugares de quadros" (e.g., recursos humanos, comunicação, controle de gestão) (Laufer, 2005: 45). Contudo, a feminização destes lugares não tem inibido a prevalência de padrões de progressão profissional diferenciados entre homens e mulheres. 
Para além de serem alvo de processos de segregação ocupacional (vertical e horizontal), de desigual remuneração, inclusive no interior da mesma categoria profissional, as mulheres experimentam, com frequência, situações de precariedade no trabalho. A sua concentração em empregos a tempo parcial, por exemplo, é reveladora deste último processo. Todavia, para muitas, este tipo de ocupação surge como uma forma de conciliarem as “obrigações” familiares com o trabalho (Giddens, 2004: 395).

A referida segregação constrói-se em duas etapas distintas: num primeiro momento, elabora-se ao longo da formação inicial de rapazes e raparigas, dando origem à chamada segregação educativa; num segundo, opera-se através da sua repartição diferenciada pelas profissões. Tal repartição reflecte mecanismos de "emparelhamento" - entre indivíduos e empregos - sexualmente diferenciados que tomam forma no mercado de trabalho (segregação profissional) (Gavray, 2006: 13).

A articulação entre o género e a formação escolar exerce assim um papel central na (re)produção dos processos de precariedade profissional feminina. Os mecanismos de distribuição dos indivíduos pelos diversos grupos socioprofissionais prolongam, quase automaticamente, a segregação educativa induzida por orientações escolares sexualmente segregadas. Tal distribuição resulta de um longo processo de socialização de homens e mulheres em licenciaturas e profissões social e culturalmente construídas em função do género.

No âmbito desta problemática, e propondo contribuir para a reflexão sobre ela, apresenta-se, de seguida, alguns "retratos" femininos de precariedade das licenciadas da Universidade do Porto. Tais "retratos ilustram que não só o género, como a licenciatura têm um peso explicativo na vivência de precariedade profissional.

\section{Vivências de precariedade por tipo de trajectória profissional}

A análise das vivências de precariedade é desenvolvida de acordo com uma perspectiva compreensiva. A partir de cada um dos tipos de trajectórias precárias 
identificadas, são apresentados dois retratos femininos, procurando-se contrastar vivências de precariedade distintas, o que é visível, não apenas nos discursos, mas também nas situações objectivas das licenciadas. Cada trajectória apresentada é precedida de uma frase-chave proferida pelas entrevistadas. As citações são escolhidas devido à sua centralidade no discurso das entrevistas e à sua dimensão significante do ponto de vista das vivências de precariedade. As narrativas são apresentadas num registo co-autoral, cruzando-se o discurso na primeira pessoa das entrevistadas, com as interpretações das autoras.

\subsection{Trajectórias precárias assalariadas com múltipla rotatividade e desemprego}

Este tipo de trajectória abrange $11 \%$ dos inquiridos e 7 entrevistados, os quais tiveram diferentes empregos e vivenciaram diversas situações de desemprego. No momento presente, alguns encontram-se empregados e outros desempregados à procura de novo emprego. Em nenhum dos empregos se verifica existir situações de desadequação entre a formação académica e a profissão que exerciam. Os seus discursos revelam uma preocupação constante face à instabilidade contratual, sobretudo aqueles que estão ligados à actividade profissional da docência.

\section{Sofia}

“Desmoralizei um bocadinho porque é chato ouvir das pessoas: está grávida não dá para lhe dar trabalho"

Sofia tem 28 anos, é solteira e tem uma filha. Licenciada em Economia, no primeiro momento da entrevista (em Maio de 2007), exercia a actividade profissional de auxiliar de armazém. É esta a sua primeira pertença profissional. Embora considere que haveria "pessoas em situações piores", refere que a situação profissional em que se encontrava era marcada pela precariedade. "Não era a situação ideal", devido à 
ausência de contrato, o que a prejudicou posteriormente, porque não teve "direito ao subsídio de desemprego". A sua percepção de que vivia numa situação precária é reforçada pelo facto do salário que auferia não corresponder à categoria que ela "efectivamente fazia”. Segundo Sofia, este procedimento é "usado sobremaneira no mercado de trabalho. (...) As pessoas não são remuneradas de acordo com as funções que exercem”.

Após a conclusão da licenciatura, acedeu ao mercado de trabalho através de um contacto informal que conhecia na empresa. Reconhece que os próprios empregadores preferem esta via, conferindo-lhe maior confiança: "saber se há algum amigo ou uma pessoa que nos foi indicada por alguém já é metade do trabalho de recrutamento feito". Refere que, no momento que se encontrava à procura de emprego, o mercado "não estava tão mau como hoje em dia”. A precariedade agravou-se e não há correspondência entre qualificação, função e remuneração.

Após a saída do primeiro emprego, a trajectória de Sofia caracteriza-se por um conjunto de situações profissionais. Seguiu-se uma fase difícil para a obtenção de emprego, devido a uma "gravidez não planeada. (...) Engravidei e então tive trabalhos recusados. Por isso durante nove meses, pelo menos quatro, que é para os infantários aceitarem as crianças, não havia hipótese de arranjar trabalho”. Durante os períodos em que esteve desempregada teve várias propostas, por parte do Instituto de Emprego e Formação Profissional, de realizar cursos de formação profissional, que considera terem sido desajustadas. Esta entidade só serve “para pôr os desempregados a passar tempo”.

Não se sente arrependida por se ter licenciado em Economia. Para além de "gostar muito", era um curso "de banda larga" que lhe permitia "trabalhar em vários sectores de actividade e ter várias profissões". Porém, não considera o curso muito ajustado às necessidades do mercado de trabalho: "a licenciatura é muito teórica e é complicado arranjar lugar para economistas em Portugal".

A situação de precariedade objectiva de Sofia alterou-se significativamente no segundo momento da entrevista (em Novembro de 2007). Presentemente é técnica oficial de contas e tem um vínculo contratual permanente numa empresa de 
contabilidade, auditoria e consultoria fiscal. Refere que a sua situação profissional actual cumpre “(...) todos os requisitos dos contratos colectivos de trabalho. Estou efectiva”, situação que lhe confere uma maior segurança profissional. Também beneficiou de um aumento da remuneração: "estou a ganhar o dobro do que ganhava antes". Tais alterações fazem-na sentir mais motivada para se empenhar no crescimento da empresa e na sua progressão profissional no âmbito da mesma: "quero ficar e quero evoluir dentro desta empresa. A empresa está em crescimento, quero é que entrem mais pessoas e vamos ver. (...) Agora sou TOC [Técnico Oficial de Contas] (...) mas depois, vamos crescendo, vamos ter outros funcionários e a minha ideia é mesmo ser ROC [Revisor Oficial de Contas]”. A motivação é acrescida pelo facto de se encontrar a trabalhar na sua área de formação o que "faz toda a diferença a nível de realização. (...) Estou bem, estou a fazer aquilo que estudei e aquilo que gosto”. A nível pessoal, Sofia conseguiu igualmente realizar um dos seus projectos pessoais mais ansiados, designadamente o de "comprar casa". Conseguiu, de igual modo, uma maior conciliação entre vida profissional e familiar: "Depois das 18 h30 estou livre para a minha filha. Dá para fazer tudo, jantar, brincar e ao fim de semana também. Estou com ela as 24 horas".

\section{Sara}

“Não foi muito fácil devido a três características: estar casada, ter uma filha e já ter 32 anos"

Sara tem 31 anos, é casada, tem uma filha e licenciou-se em Geografia. Em termos de pertença profissional considera que a sua "habilitação não é para professora, é para geógrafa", mas a profissão mais duradoura que exerceu foi de professora. No entanto, admite que a sua actividade profissional é aquela que se adequa à sua prática profissional do momento.

Quando foi entrevistada pela primeira vez, em Abril de 2007, exercia a sua actividade profissional como técnica administrativa e coordenadora pedagógica. Nesta 
altura considerava que a sua situação profissional era "bastante precária”. Como “coordenadora pedagógica, trabalhava 8 horas por dia, incluindo ao Sábado”. À sua situação de precariedade, aliava-se o sentimento de frustração de expectativas que manifesta ao afirmar: "quando me candidatei ao ensino superior eu tinha em vista, quando acabasse a minha licenciatura, conseguir um emprego ligado à área que tinha tirado”. Critica a licenciatura precisamente devido à falta de informação sobre as saídas profissionais: "ninguém me soube dizer, nessa altura, que as saídas profissionais eram muito complicadas".

Acedeu ao mercado de trabalho logo após ter concluído a licenciatura, numa empresa de investigação. Três meses após encontrava-se desempregada. Encetou um processo de procura de emprego recorrendo a todos os meios, formais e informais. $\mathrm{O}$ "mercado de trabalho estava péssimo e continua complicado". Só com "uma boa cunha" é que se consegue aceder a um emprego. Afirma ainda que as condições de exercício do trabalho e remuneratórias se degradaram, havendo licenciados "a ganhar o ordenado mínimo".

No segundo momento em que é entrevistada (Novembro de 2007), Sara encontra-se a realizar duas actividades profissionais em simultâneo: uma actividade de auditoria interna e a docência num centro de estudos. Embora considere que, com a auditoria, tenha conseguido maior segurança e estabilidade, uma vez que se encontra vinculada por um "contrato a tempo incerto" e que "só se o shopping fechar" é que a “podem mandar embora”, já quanto ao centro de estudos, não tem qualquer contrato. "Isso quer dizer que em Julho" a podem “dispensar”. Por esta razão, considera que sua situação profissional actual continua a corresponder a uma situação precária. Em termos remuneratórios, não está tão dependente do centro de estudos, pois só dá "explicações duas vezes por semana”. Em relação ao seu emprego como auditora diz: "não me posso queixar, que o Belmiro paga bem”.

A mudança de actividade profissional acabou por ter repercussões a nível familiar, uma vez que só exerce a auditoria ao fim-de-semana: "neste momento, tenho mais tempo para estar com a minha filha durante a semana, mas ao fim de semana ela 
é penalizada". Afirma que a sua filha, nota que a mãe "ao fim de semana, não está". Nesta altura são os avós a assegurar os cuidados da filha, "porque o marido não tem paciência nem jeito para estar com ela".

A trajectória profissional de Sara é, deste modo, marcada, fundamentalmente, por duas actividades profissionais. Uma de docência num centro de estudos e outra como auditora num centro comercial. Esta simultaneidade e dualidade reflectem-se nas suas manifestações de identificação profissional: "parecendo que não, como é que eu hei-de dizer qual é a minha profissão? Verdadeiramente era geógrafa que eu queria ser. Só que o mercado de trabalho não deixa". Sara acumula um emprego não precário (auditora interna) e um outro precário (centro de estudos, sem relação contratual). Esta última situação fá-la sentir que ainda se encontra numa situação de precariedade o que é reforçado pelo facto de se encontrar a trabalhar numa área distante da sua formação disciplinar original. Contudo, não desistiu de estar "sempre a procurar nos jornais, na internet" ofertas ligadas à sua área. Porém, também acalenta como projecto profissional futuro o desejo de continuar ligada à auditoria, já que "gosta de ser auditora".

\subsection{Trajectórias precárias de trabalhadores independentes com elevada rotação}

Trata-se de trajectórias de trabalhadores independentes que totalizam 10,4\% dos licenciados inquiridos e sete entrevistados. São caracterizadas por uma rotatividade entre três ou mais empregos regulares, uma fraca incidência de situações desemprego e uma melhoria da situação de precariedade do primeiro para o emprego actual.

\section{Carolina}

\section{"Preciso desta estabilidade"}

Carolina, licenciada em Gestão, é solteira e não tem filhos. Terminou a sua licenciatura em 2003 e desde essa data mudou de actividade profissional diversas vezes. 
A rotação entre actividades profissionais diversas permitiu-lhe adquirir conhecimentos e cimentar competências. No primeiro momento em que foi entrevistada (em Maio de 2007), desempenhava a actividade profissional de produtora de dança, uma situação que considerava ser precária, por se encontrar num papel de "falsa trabalhadora independente", isto é, como a própria entrevistada refere, "para mim, quem trabalha a recibos verdes, numa empresa fixa, com horários a cumprir e etc., está sempre numa situação precária". No segundo momento em que foi entrevistada (em Maio de 2007), a precariedade subjectiva deixa de ser uma realidade. Como delegada de informação médica, e embora tenha um vínculo contratual precário, perspectiva transitar para o estatuto de trabalhadora efectiva, afirmando que "normalmente é assim que funciona, quase toda a gente passa a efectivo".

Manifesta uma atitude crítica face ao mercado de trabalho. Apesar de avaliar a sua integração no mercado de trabalho como "muito boa e fácil", afirma que o desemprego está a aumentar, que o empregador assume uma postura de "cada vez mais exigir muitíssimo dos trabalhadores em termos, por exemplo, de horas de trabalho (...) que nem sempre se traduz em maior produtividade paga cada vez menos". E reforça esta representação no segundo momento que foi entrevistada referindo que "desde que comecei no mundo do trabalho tenho a percepção de uma exigência brutal em termos de horário de trabalho e nem sempre o número de horas de trabalho tem uma relação directa com a produtividade". Não se identifica com o seu título académico, de gestão, pois "eu nunca fui gestora de coisa nenhuma".

Em termos de vida familiar, entre Maio e Dezembro de 2007, Carolina iniciou uma vida pessoal autónoma da família de origem. Perspectiva, em breve, viver em conjugalidade e projecta, a médio prazo, ter filhos. Como refere, as suas expectativas são "comprar casa para o ano e depois espero viver com o meu namorado, dentro em breve, e depois, tenho 28 anos, lá para os 30, ter um filho".

Trata-se de uma entrevistada cuja trajectória profissional é de mudança pessoal e profissional, tendo como expectativa aceder a uma posição não precária no mercado de trabalho e ter filhos. É de salientar o facto de ser uma trajectória constituída por 
diversos empregos de conteúdo diferente, que lhe permitiram "um sentido de adaptação muito fácil, em qualquer circunstância e em qualquer zona".

\section{Antónia}

\section{"Todos os anos é uma luta constante para conseguir arranjar trabalho"}

Antónia, solteira, é licenciada desde 2003 em Línguas e Literaturas Modernas e encontra-se, em Novembro de 2007, a leccionar numa escola secundária. Com 26 anos de idade, esteve numa situação de desemprego de inserção durante um ano. Avalia a sua transição ao mercado de trabalho como "muito difícil", decorrente da procura intensiva de ofertas de emprego que realizou e ainda hoje realiza, frequentemente sem sucesso.

Vivencia uma situação de precariedade objectiva e subjectiva, patente, em particular, no facto de ser uma trabalhadora independente. Afirma, deste modo: “é precário no sentido em que eu não tenho um contrato de trabalho e se tiver um acidente de trabalho, se tiver doente ou qualquer coisa não tenho aquela coisa que o contrato nos permite ter aquelas regalias". E esta situação, vivida já há algum tempo, condiciona as suas perspectivas futuras, pois "chega a uma altura em que nós começamos a olhar para a frente e a ver, a ter perspectivas de futuro e a ver que as perspectivas estão a ser goradas".

Apesar de permanecer numa situação de precariedade, no segundo momento em que foi entrevistada, Antónia manifesta-se muito mais satisfeita na escola onde se encontra a trabalhar: "a nível de motivação, mudou muito, porque eu agora tenho mais motivação, porque estou numa escola diferente, com um ambiente diferente, trabalho muito melhor, gosto muito mais de cá estar, estou bem inserida".

A sua leitura do mercado de trabalho é, deste modo, pessimista, sendo a tendência para a deterioração das condições, "porque todos os anos temos uma série, milhares de licenciados que estão desempregados". Acrescenta ainda que "o mercado de trabalho não respeita as pessoas, não respeita leis, não respeita listas, não respeita 
regras nenhumas. É cada um por si, cada empresa faz aquilo que quer, cada instituição faz aquilo que lhe apetece".

Antónia identifica-se como professora, ou, precisando melhor, "ser professora no sentido convencional de estar numa escola a tempo inteiro a dar aulas, não sou nesse sentido. Mas a minha profissão, acima de tudo, é ensinar, seja ser docente, monitora ou formadora ou o que queiram chamar, é ensinar. A minha profissão é ensinar". Escolheu a licenciatura pela sua "paixão pelos livros, pela escrita e pela literatura, um amor incondicional que é das coisas mais fortes que eu tenho". No entanto, avalia a licenciatura de forma muito negativa, frisando a componente excessivamente teórica e a reduzida utilidade das disciplinas pedagógicas e psicológicas. O que aprendeu não a prepara, designadamente para a "heterogeneidade das turmas" e para os "diferentes ritmos de aprendizagem. (...) Precisa de uma componente prática muito maior, é muito teórico, mesmo as cadeiras pedagógicas".

A entrevistada coabita com a família de origem, considerando que é a sua vida profissional que impede a constituição de um núcleo familiar autónomo, ainda que isolado.

Antónia vive de forma intensa a sua situação de precariedade, considerando que deveria haver uma maior protecção dos professores. A sua marcada dificuldade em conseguir um emprego estável do ponto de vista contratual encontra-se associado à situação global dos professores, afirmando: "parece-me que o mercado de trabalho já nos rejeita". Estamos, deste modo, perante uma manifestação de insegurança profissional, alicerçada na situação geral do grupo profissional dos professores e no decréscimo de posições disponíveis no mercado de trabalho, em particular ao nível do ensino público. Neste sentido, o futuro é marcado por uma forte incerteza, visível na dificuldade em estabilizar e em concretizar projectos no futuro. 


\subsection{Trajectórias precárias de trabalhadores independentes com razoável estabilidade}

O tipo de trajectória precária de trabalhadores independentes com razoável estabilidade contempla 7,9\% dos inquiridos e 6 licenciados entrevistados. Constitui o único tipo de trajectória precária marcado pela permanência num mesmo emprego.

A precariedade da trajectória decorre igualmente da esmagadora maioria dos inquiridos ter um vínculo laboral precário e trabalharem a tempo parcial. Independentemente de se encontrarem ou não a desempenhar actividades na sua área de formação disciplinar, a maior parte das entrevistadas considera que a sua situação profissional é precária.

\section{Elisa}

"Uma pessoa não consegue programar sequer uma vida durante um ano"

Elisa tem 25 anos é solteira e não tem filhos. Licenciou-se em Arqueologia e no primeiro momento em que foi entrevistada identificou-se profissionalmente como "técnica superior de arqueologia". Faz uma avaliação positiva do curso, salientando apenas como défice da mesma "a não obrigatoriedade" de frequência das escavações.

Passados cinco meses Elisa encontra-se a explorar um bar. A sua situação profissional é caracterizada pela precariedade e instabilidade, condições que afectam, grosso modo, o grupo profissional dos arqueólogos. Refere que a arqueologia, particularmente no domínio das escavações, está muito dependente das flutuações do mercado e se, em determinados períodos, a procura de mão-de-obra é intensa, noutros é reduzida: "há alturas em que há muitas escavações, a mesma empresa anda à procura de várias pessoas como, de repente, o mercado não está a precisar de tantas escavações e uma pessoa acaba por ficar uns mesitos em casa". A sua situação de precariedade objectiva impede-a de fazer planos, mesmo a curto prazo, devido à volubilidade do mercado de trabalho: "é muito precário mesmo, porque uma pessoa 
não consegue programar sequer uma vida durante um ano”. Situação que se agrava devido ao carácter informal das redes de acesso ao mercado de trabalho na área da Arqueologia: "quando aparece alguma coisa tentamos sempre ver quem está livre para poder ir fazer o trabalho. Indicámo-nos uns aos outros".

Apesar de passar a ser responsável pela exploração de um bar, a percepção de precariedade objectiva de Elisa manteve-se no segundo momento que foi entrevistada, devido à morosidade e complexidade inerente à criação de um "negócio por conta própria. Estou a ter outros problemas burocráticos (...) os entraves são tantos, são precisas tantas coisas que uma pessoa desiste. Chega a um ponto em que o investimento que se tem que fazer, só o consegue recuperar em quatro anos, é preferível não arriscar". Esta situação condu-la “mais uma vez" a "ter que procurar outra coisa”.

Elisa considera que a vida profissional tem influência na vida conjugal. Quando namorava tudo dependia da sua profissão: "se queríamos marcar alguma coisa juntos, estava dependente se estava ou não em casa. Marcar férias é impossivel”. A ausência de estabilidade financeira também é importante: "não tenho trabalho certo. Onde é que eu ia comprar uma casa?" É necessário "encontrar uma certa estabilidade para poder avançar depois".

A trajectória profissional da entrevistada é diversificada. Licenciada em Arqueologia, salienta as aprendizagens obtidas através das escavações como sendo fundamentais na sua formação. Da sua experiência de gestão de um bar, manifesta que “não quer fazer isso para o resto da vida”. Resolveu frequentar uma pós-graduação em Museologia, área que considera ter "outra abertura profissional”. Embora tenha consciência das dificuldades, tem como projecto profissional futuro encontrar emprego na área da museologia. 


\section{Catarina}

\section{"Tenho todo o trabalho que preciso"}

Catarina é casada, tem um filho e licenciou-se em Línguas e Literaturas Modernas. Tem uma visão positiva da formação que obteve no curso: "a licenciatura serve como um ponto de partida essencial em termos académicos e científicos".

Embora seja "trabalhadora por conta própria”, considera que a sua situação profissional não é precária, fundamentalmente porque a actividade de tradutora lhe permite ter todo o "trabalho que precisa", até tem "trabalho a mais". A sua inserção no mercado de trabalho é "muito particular", não tendo realizado "uma procura activa de emprego". Quando terminou o curso, contactou uma pessoa numa empresa conhecida, abordando-a informalmente: “olá, lembraste-me de mim? Fiz o curso e era para veres se estás interessada?" Considera ter tido "muita sorte” porque o mercado de trabalho é "muito precário" e "instável”. Por isso, pensa que é fundamental a diversificação dos contactos pessoais. Mesmo que as condições laborais não sejam as melhores, principalmente devido aos baixos salários, refere que "não há grandes queixas, porque temos todos a noção que hoje em dia é necessário manter o emprego".

Vê algumas vantagens em ser trabalhadora independente. Não tem horários rígidos, pode exercer a sua actividade em qualquer área geográfica e, acima de tudo, "eu trabalho com duas empresas, uma é de Barcelona e outra é de Lisboa e eu moro no Porto. Portanto, se trabalhasse fisicamente em qualquer uma delas, não podia trabalhar na outra e teria de mudar de casa". Ao contrário de outros tele-trabalhadores, a solidão nunca se apresentou como um problema, até porque a comunicação com as empresas é "muito acentuada e próxima".

Entre os dois momentos de realização das entrevistas (Abril e Novembro de 2007) não houve alterações ao nível da sua situação profissional. No entanto, adoptou uma atitude mais pró-activa através do envio de currículos e da divulgação do seu trabalho na internet, porque se apercebeu "que o mercado está instável" e que a 
empresa com que trabalha "pode deixar de dar trabalho". Também concluiu o Mestrado em Terminologia e Tradução, o que lhe trouxe mais "oportunidades".

$\mathrm{O}$ facto de exercer a sua actividade profissional em casa permite-lhe uma melhor conciliação com a vida familiar. Porém, admite que por vezes, a sua actividade sai prejudicada, porque para "manter a casa em condições e para tratar das coisas todas, passa a noite toda a trabalhar”. A sua vida profissional não afecta, de igual modo, a estabilidade conjugal. Embora não exista uma divisão de tarefas domésticas claramente assumida com o marido, Catarina refere que "quem está e pode fazer faz e pronto". Tem igualmente o apoio da mãe e da sogra ao nível da guarda do filho, sobretudo quando há muito trabalho. Contudo, lamenta não ter muito tempo para ela própria: "não tenho tempo para estar sozinha. Ou estou a trabalhar ou estou com a família. Para ir ao cabeleireiro é uma desgraça”. Também não dispõe de tempo para a "vida social”.

Catarina tem uma trajectória profissional como trabalhadora independente mais focalizada nas vantagens decorrentes desta posição no mercado de trabalho. Embora reconheça que o mercado de trabalho está cada vez mais instável, revela uma atitude pró-activa, apostando na diversificação dos conhecimentos e na exploração de oportunidades de trabalho diversas. Os seus projectos futuros passam pela realização de um doutoramento, caso consiga uma bolsa para o efeito. Perspectiva ainda criar uma empresa com o marido, com vista a "apostar mais na tradução técnica e na formação de tradutores". Também deseja "abrir um centro de estudos de inglês para crianças dos 3 meses aos 14 anos". A nível pessoal pretende ter outro filho "para breve".

\subsection{Trajectórias precárias de investigador-bolseiro}

Estas trajectórias profissionais representam apenas 3,4\% do total da amostra dos licenciados inquiridos e 4 entrevistados. São caracterizadas, maioritariamente, por uma condição actual perante o emprego de bolseiro de investigação, de mestrado ou de doutoramento. Actualmente a ausência de vínculo contratual é sinónimo de 
precariedade, ainda que todos exerçam a sua actividade a tempo inteiro. Não vivem uma situação de desclassificação profissional, na medida em que exercem funções altamente qualificadas, integrando-se em instituições de Investigação e Desenvolvimento. Trata-se de sujeitos para quem a investigação constitui uma actividade profissional à qual, genericamente, visam dar continuidade, numa perspectiva de prossecução de um trajecto altamente qualificado numa área profissional onde se sentem intrinsecamente realizados.

\section{Madalena}

\section{"Somos um bocado escravos do projecto de doutoramento"}

Madalena, socióloga desde 2004 é bolseira de doutoramento. Solteira e sem filhos, considera que vive uma situação precária, pois as bolsas sucedem-se e não há qualquer garantia “de um emprego fixo". A precariedade, na perspectiva da entrevistada, associa-se à ausência de qualquer tipo de direitos e de "garantia que vamos ter um emprego para a vida". Esta situação de incerteza condiciona outros projectos, nomeadamente a constituição de uma vida familiar autónoma. A bolsa de doutoramento que actualmente dispõe não foi a sua primeira actividade profissional. Desde sempre exerceu actividades de investigação, em moldes diversos, o que marca a continuidade da sua trajectória.

A sua leitura do mercado de trabalho assume alguns traços de optimismo, afirmando que as elevadas taxas de desemprego marcam "uma coisa temporária. (...) Tenho expectativas de que vai melhorar bastante em 2008. (...) Como estamos a crescer acima da média de muitos países da União Europeia, acho que vai ser uma situação um pouco transitória". Todavia, não deixa de referir que as entidades empregadoras tendem a fomentar situações precarizantes, na medida em que "quando o empregador se apercebe que há muito trabalho que pode ser feito de graça começa a recrutar pessoas e as pessoas ficam com aquela ideia que em breve poderão ter um contrato de trabalho e depois isso não acaba por acontecer". Particularmente em 
qualquer "área social", a prestação de serviços constitui agora o vínculo laboral por excelência em detrimento dos contratos de trabalho e "os recibos verdes são o prato do dia". Em relação ao seu primeiro emprego, refere que “a maior parte das pessoas que já lá trabalhavam há quatro anos e há pessoas que trabalham há dez anos a recibos verdes que não têm qualquer garantia. Por mais que se ganhe algum dinheiro as pessoas nunca conseguem organizar uma vida porque não têm nenhuma segurança".

Madalena manifesta uma forte identificação com o título académico e profissional, afirmando que "responderia imediatamente socióloga mas, ao mesmo tempo, também poderia dizer antropóloga urbana". Esta última surge por força do seu projecto de doutoramento. Refere que à formação académica falta uma componente prática e que "em termos de intervenção, não se reflecte, cientificamente, sobre isso, porque não é só uma questão de ter prática, acho mesmo que a nível da reflexão teórica é preciso dar mais exemplos de trabalhos, na prática, de intervenção". Considera ainda que a licenciatura tem lacunas ao nível dos instrumentos técnicos, exemplificando: "estou a falar da construção de um guião, estou a falar até de coisas tão básicas com se faz uma bibliografia, coisas assim pragmáticas". Assim, a adequação da formação académica é mais notória no domínio dos conhecimentos teóricos.

A entrevistada manifesta-se satisfeita com a sua integração no centro de investigação onde se encontra, frisando, em particular, a autonomia na realização do seu trabalho. A sua actividade presente constitui, de igual modo, um percurso de aprendizagem, na medida em que "continuas sempre a ler e a escrever sobre isso e a fazer mais pesquisa".

Afirmando a prioridade conferida à actividade profissional em detrimento da conjugalidade, não deixa de equacionar projectos futuros de “constituir uma família, mas, para isso, preciso de encontrar a pessoa certa". A maternidade também está presente nos seus projectos futuros, ao referir que "ter filhos é uma coisa que me começa a estar na cabeça de alguma maneira, deve ser do ciclo biológico". 
Mais concretos são os seus projectos profissionais de terminar a tese de doutoramento e prosseguir a sua trajectória de investigação. Neste domínio, "gostaria de criar uma associação, uma cooperativa de investigação".

\section{Susana}

"Sou investigadora e docente, nunca psicóloga"

Susana, licenciada em Psicologia desde 2001, é casada e não tem filhos. Tem 28 anos de idade e é bolseira de doutoramento. A sua bolsa estava, no primeiro momento em que foi entrevistada (Abril de 2007), prestes a terminar, o que a colocava perante uma situação de mudança a curto prazo. Associada a esta situação, afirma que "é uma situação precária, porque a bolsa de doutoramento é sempre uma situação que sabemos quando vai terminar".

Em Dezembro de 2007, a entrevistada integrou o corpo docente de uma escola superior de educação, onde exerce funções como docente a tempo parcial, e integra um centro de investigação de uma Faculdade, o que lhe permite manter a sua actividade de investigação. Tem tido um processo de integração complexo, pois "é um meio muito diferente".

Susana auto-identifica-se como "investigadora e docente" e "nunca psicóloga". Aquando da escolha da licenciatura, a sua primeira opção foi medicina, "porque gostava de ser médica e sabia que ia ter boas saídas em termos profissionais". Avalia a sua formação académica como "muito boa" e adequada, "devido às funções que exerço (...) estou a fazer investigação em psicologia". Neste sentido, mobiliza mais os conhecimentos de cariz teórico.

No acesso ao mercado de trabalho, Susana adoptou uma atitude de procura activa: "enviei currículos para muitos gabinetes, escolas, colégios, jardins-de-infância, para a Escola Superior de Educação do Porto, de Viana; cheguei a mandar para a Universidade Católica, enviei para várias escolas. Também respondi a um concurso da $A M I$ '. Esta é contingente com a sua leitura do mercado de trabalho, considerando que 
para os licenciados é "muito mais difícil" aceder a um emprego. Refere igualmente o crescimento do desemprego e a aparente contradição com o facto de haver vagas para empregos não preenchidas: “eu ouço nas notícias muitas vezes que há imensas pessoas desempregadas e a taxa continua a subir e fico muito surpreendida quando se chega ao final do ano e vêm estatísticas de emprego a dizer que as ofertas de emprego não foram todas preenchidas". Paralelamente, e atestando uma desadequação qualitativa entre oferta e procura de emprego, salienta que o excesso de licenciados constitui um dos factores que contribui para o facto de os empregadores adoptarem medidas de gestão flexíveis e precarizantes: "é muito complicado, é muito difícil neste momento. Ir para o quadro nem se fala e mesmo a contrato não é muito fácil, no momento, conseguir emprego".

O doutoramento constituiu uma actividade extremamente importante a diversos níveis, de entre os quais o da aprendizagem, na medida em que permitiu o desenvolvimento de "competências relacionadas com a investigação, em termos de metodologia, em termos de estatística", conhecimentos esses que "serão úteis ao longo de toda a vida quer tenha oportunidade de continuar ligada à investigação, quer não tenha". Também a docência constitui uma aprendizagem enriquecedora "em termos de dinâmica institucional".

Do ponto de vista da vida familiar, a entrevistada considera que o doutoramento "afecta negativamente a vida conjugal", pois "é um trabalho muito autónomo, não é das 9 às 5, é sempre hora de trabalho, à noite, ao fim-de-semana, é sempre altura para trabalhar".

As suas perspectivas profissionais futuras são positivas, na medida em que "as universidades e os institutos politécnicos precisam de professores doutorados". Por sua vez, equaciona a hipótese de avançar para um pós-doutoramento. Relativamente à vida familiar perspectiva concretizar a maternidade, ao afirmar " $е$ и e o meu marido estamos a pensar mudar de casa brevemente e pensar ter filhos, acho que está na altura". 


\subsection{Trajectórias precárias assalariadas pontuadas pelo desemprego}

Ainda que em número residual (1,9\% dos inquiridos), as trajectórias precárias destes trabalhadores destacam-se pela sua contínua vulnerabilidade no mercado de trabalho. Contemplam 3 entrevistados.

Os seus discursos revelam uma preocupação constante face à insegurança e instabilidade sentida nas áreas da sua actividade profissional e, consequentemente, uma certa frustração de expectativas pela ausência de uma relação contratual que lhes garanta alguns direitos fundamentais.

\section{Mafalda \\ "Sinto-me muito bem em contexto de sala de aula mas na instituição não sou parte integrante"}

Mafalda tem 31 anos, é casada e tem uma filha. Licenciada em Filosofia, identifica-se profissionalmente como sendo professora: "não sei bem, mas acho que sim". Refere a componente demasiado teórica da licenciatura, mas também salienta a importância do conhecimento de base adquirido: "são essas bases que permitem saber onde procurar e que autores são interessantes trabalhar".

Considera que a sua situação profissional é precária, sobretudo devido à instabilidade e insegurança sentida anualmente: “todos os anos há uma preocupação. Pelo menos se houvesse aquela confirmação de que se pode todos os anos, contar com trabalho”. A sua situação é vivida como sendo “totalmente precária”, porque não corresponde a "uma situação de estabilidade a 100\%, com um contrato assegurado por mais de um ano”. Contudo, também refere que é importante relativizar o próprio conceito de precariedade: "se considerarmos que o normal é a pessoa estar aberta à mobilidade, (...) se adoptarmos como normal essa questão dos recibos verdes, ter outro tipo de relação com a entidade, então aí é mais complicado de gerir isso. Acho que ainda há uma série de estereótipos relativamente a isso”. 
Mafalda sempre trabalhou no ensino público e apesar de considerar que o "mercado de trabalho está complicado", recorda que a sua primeira experiência profissional não correu mal, pois conseguiu logo um horário que, "embora não completo, 12 ou 16 horas", foi "muito bom. Podia haver uma esperança".

Após 8 meses da primeira entrevista (em Abril de 2007) Mafalda encontra-se a trabalhar numa escola pública com um "horário de cinco horas”. Mantém a percepção de que vive uma situação de precariedade profissional, considerando-a comum aos docentes: "é uma situação que não é só minha. (...) Todos os anos, chegamos a Junho, Julho e até Setembro espera-se, vamos lá ver o que vai acontecer”. Acrescenta ainda que a situação de precariedade se agravou devido "às medidas que foram implementadas pelo Ministério da Educação. (...) Para os professores contratados nota-se um decréscimo de horário para trabalhar”. Tal deve-se, na sua opinião, ao facto de as colocações "estarem a ser feitas de forma mais organizada”, impedindo os "professores de carreira de ficarem com horário zero". As condições laborais no ensino agravaram-se para os professores contratados, quando comparadas com as que são praticadas pelas empresas de trabalho temporário: "se é preciso um professor até ao final das aulas, é no final das aulas e a pessoa sai e deixa de ter direito ao subsídio de férias".

As dificuldades vividas na esfera profissional não interferem, na sua perspectiva, com a estabilidade conjugal: "não se cria espaço para a conflitualidade”. No entanto, nos momentos de maior cansaço e de "sobrecarga de tarefas", "as coisas naturalmente manifestam-se", sobretudo ao nível familiar: "em épocas de testes não existem fins-de-semana se quisermos cumprir os prazos e isso acaba por afectar a vida familiar”. A maternidade obriga Mafalda a uma gestão do tempo mais eficaz. Conta com o apoio da família com vista conciliar a vida profissional e familiar: "desde o ir buscar à escola, quem vai, consoante os horários de cada um; quem está ao jantar, quem não está. Depende da disponibilidade de cada um no momento”.

Mafalda apresenta uma trajectória profissional diversificada. Começou por trabalhar na área dos recursos humanos, o que a conduziu a iniciar a frequência de uma 
licenciatura nesta área, que logo abandonou. O seu emprego seguinte foi no sector comercial de uma empresa, e antes de ingressar no ensino público, teve uma experiência de leccionação no sector privado. $\mathrm{O}$ facto de se encontrar actualmente ligada a um projecto na área de "produção de manuais escolares" permite-lhe compensar o seu horário reduzido em termos de docência. Manifesta-se crítica face à sua licenciatura, afirmando que esta deveria ter em conta as "necessidades do mercado de trabalho nacional”. Salienta ainda a importância da actualização de conteúdos, sobretudo ao nível do estudo de filósofos contemporâneos e temas actuais, como é o caso do ambiente. Tem a expectativa de vir a ser colocada no ensino público, mas a sua prioridade é a família: “a minha situação vai ser sempre muito precária, sobretudo porque sei quais são os critérios de escolha; primeiro está a família e isso vai sempre condicionar a minha própria carreira”. Do seu projecto pessoal faz parte o desejo de "ter mais um filho", mas, mais uma vez, "está tudo dependente da questão profissional". Como projecto profissional futuro tem a "esperança" de continuar a leccionar.

\section{Rute}

"Somos a geração mil euros. Não saímos dos mil euros, um bocadinho mais, um bocadinho menos é quanto nos pagam"

Rute tem 37 anos, é solteira e não tem filhos. Licenciou-se em História. É formadora e considera a sua situação profissional como "bastante precária”, pois só tem emprego sempre que é solicitada pelo empregador. Actualmente sente-se duplamente arrependida, não só em relação à escolha da licenciatura: "se eu tivesse escolhido outra coisa, teria sido melhor"; como pelo facto de ter recusado um emprego na banca: "fiz muito mal, nesta altura era bancária, estava a trabalhar há não sei quantos anos, com um bom emprego em vez de estar nesta situação”. Para além de não ter conseguido aceder a uma posição no mercado de trabalho na sua área de formação, Rute considera que possui excesso de qualificações "para alguns tipos de empregos. 
(...) Tinha o curso de programação de computadores, imensos conhecimentos de línguas, curso de secretariado, tinha uma série de coisas e não conseguia arranjar emprego". Tudo isto agrava o seu sentimento de frustração profissional.

Quando concluiu o curso esteve cerca de dois anos no desemprego. Recorda-se da experiência do estágio num museu que, apesar de gratificante, não lhe "serviu de nada para o futuro”. Através do Instituto de Emprego e Formação Profissional frequentou vários cursos, os quais pensava que a "iriam ajudar". Recorreu a todos os meios, inclusive às "cunhas" para aceder a um emprego. Frequentou uma pósgraduação em Museologia e uma outra em Artes Decorativas, como estratégia de "valorização" do currículo profissional. Mas, como afirma, "foi dinheiro deitado ao lixo". O mercado de trabalho "ficou pior" e é incapaz de absorver o excesso de licenciados, igualmente por força dos formados pelas universidades privadas. $\mathrm{O}$ excesso de oferta de licenciados gera um decréscimo do valor dos salários. Rute afirma compreender a posição dos empregadores e "se estivesse no lugar deles fazia o mesmo. Há muitos licenciados dispostos a trabalhar e os empregadores tendem a reduzir as remunerações". À “injustiça das remunerações" junta-se a desqualificação dos licenciados. No seu caso, considera que a idade constitui um entrave a um emprego mais estável: "fiz há pouco tempo 39 anos. É mais dificil entrar no mercado de trabalho com algo mais sólido”.

Apesar da situação em que se encontra, Rute considera que a sua licenciatura seria totalmente adequada "se estivesse a dar História”. Porém, admite que "para ficar bem a nível financeiro teria que fazer uma reestruturação completa" da sua vida. Afirma, a este propósito: “a licenciatura em História de Arte não me serve para nada”. A instabilidade profissional tem interferido com os seus projectos pessoais. Quis casar enquanto estava a tirar a licenciatura, mas admite que "não havia hipótese”. Acalenta, no entanto, o projecto de ir viver com o namorado, pois afirma "estar farta de viver na casa da irmã’".

Passados nove meses do primeiro momento em que foi entrevistada (Dezembro de 2007), Rute continua a considerar a sua situação profissional precária. Em breve 
terminará o seu segundo contrato a tempo inteiro com as Pousadas de Portugal, enquanto profissional da área comercial, desconhecendo se será renovado ou não. No entanto, não se considera “completamente mal”, uma vez que tem um contrato e a “Segurança Social paga” se for colocada novamente no desemprego.

Rute é uma entrevistada com uma trajectória profissional marcada por um forte investimento na sua formação com vista à valorização do seu currículo. Todavia, até ao momento presente, não teve contrapartidas do investimento que realizou. Afirma ainda que mudou de postura na sua relação com o mercado de trabalho: "eu estou bastante mais prática”. Encara o futuro com optimismo devido à extensão dos conhecimentos que possui e à "vontade que tem de dar a volta por cima”. Tem como projecto profissional futuro "trabalhar numa empresa na parte de apoio a clientes, recursos humanos". Deseja casar. Não sabe se vai ter filhos ou não. "Queria muito”, mas também quer "ser feliz e viajar mais".

\subsection{Trajectórias de desempregados de inserção}

É um tipo de trajectória que abarca 3,2\% dos licenciados inquiridos e cinco entrevistados. Trata-se de indivíduos que nunca transitaram para o mercado de trabalho, permanecendo no desemprego. Os seus discursos evidenciam bem esta situação.

\section{Matilde}

\section{"Sinto-me frustrada, é o termo"}

Matilde, licenciada em Línguas e Literaturas Modernas, desde 2003, é casada e tem dois filhos. Com 42 anos de idade, relaciona a sua situação de desemprego com as características do mercado de trabalho, ainda que também se associe às suas opções ao nível da vida familiar. Assim, considera que as razões da sua situação de desemprego se prendem: por um lado, com a ausência de informação acerca das saídas profissionais, pois, "se houvesse mais informação, eu acho que teria enveredado por outros caminhos 
que não este e teria chegado a outra área"; por outro lado, com a inexistência de emprego para os licenciados na respectiva área.

A entrevistada manifesta um sentimento de frustração ao nível profissional: "não vou dizer parasita, porque não sou, porque trabalho muito em casa, tenho dois miúdos, mas sinto-me um bocado frustrada (...). Sinto-me frustrada, é o termo". Por sua vez, também refere a idade como um factor que condiciona o acesso ao mercado de trabalho.

Não tendo conseguido aceder ao mercado de trabalho, Matilde tem uma leitura crítica do mesmo, classificando-o como "péssimo", por força da falta de emprego, mas também das condições de trabalho existentes em termos, designadamente, do excesso de horas de trabalho e das baixas remunerações.

Embora desempregada, considera-se "professora". Manifesta a utilidade da sua licenciatura em áreas diversas, tais como o turismo ou a tradução. No entanto, não o é para a docência, face à sobrelotação do mercado de trabalho. Afirma, a este propósito: "eu tenho concorrido com os currículos e a falar a pessoas amigas a ver se me arranjam (...). "Agora já estou por tudo, já disse que até aceito trabalho como telefonista e tudo, desde que seja uma coisa honrada". No entanto, "ainda não consegui nada, mas tenho mandado currículos para as escolas, principalmente para as escolas e tenho concorrido aos mini - concursos". A situação da entrevistada é, como se pode concluir, vivida como preocupante.

Escolheu a licenciatura que completou pelo "sonho de dar aulas", mas, face à situação do mercado de trabalho, põe em causa a sua adequação: "a minha área está sobrelotada, há imensos professores de Português e de Francês [e] cada vez mais os miúdos tendem a optar por outras línguas que não o francês". Verifica-se, deste modo, uma expectativa profissional não concretizada.

Casada há 16 anos, a entrevistada considera que a sua situação de desemprego condiciona a vida familiar em termos financeiros, pois "temos de abdicar de certas coisas". Na medida em que não tem actividade profissional, pode dedicar mais tempo à educação dos filhos e às actividades domésticas. É Matilde que assegura a totalidade 
destas tarefas. O marido "na casa, verdade seja dita, não faz nada a não ser que seja uma lâmpada que precisa de ser mudada, um fio que precisa de ser arranjado. Agora de resto não; quando chega a casa já tem tudo feito".

Matilde constitui assim o caso de uma pessoa que nunca acedeu ao mercado de trabalho e que, paralelamente, assumiu as tarefas domésticas e familiares praticamente na íntegra. Os seus projectos futuros acompanham de perto a sua situação presente: manutenção na situação de desemprego e prossecução das actividades familiares e domésticas.

\section{Rita}

\section{"O mercado para licenciados está difícil"}

Rita, licenciada em Sociologia desde 2004, mantém-se, em Dezembro de 2007, desempregada. Com 28 anos de idade solteira e sem filhos, vive com preocupação a sua situação.

A sua identificação profissional é como "licenciada em Sociologia", não assumindo o título profissional de socióloga, pois nunca exerceu. Afirma mesmo: "acho que não tenho profissão, estou à procura de emprego". A não identificação com o título escolar poderá estar relacionada com a perspectiva crítica que manifesta relativamente à licenciatura, afirmando que "faz-nos falta a componente prática" e que "para um curso como o nosso podia haver estágios curriculares ao longo do curso, eu acho uma coisa facilitadora, porque dá-nos um contacto com o mercado de trabalho".

A ausência de emprego conduz Rita a afirmar a sua desmotivação, e que, se pudesse voltar ao passado, "às tantas tinha tirado um curso técnico-profissional". O mercado de trabalho "não tem infra-estruturas, nem está estruturado de forma a absorver o contingente de licenciados que sai". Do lado dos empregadores, o excesso de licenciados potencia a deterioração das condições de trabalho, o que abarca, designadamente, a incompatibilidade entre remuneração e função ou a sobrecarga horária. 
Rita tem mantido uma estratégia de procura activa de emprego, a par da realização de cursos de formação, mas afirma que a ausência de experiência profissional é um factor importante no acesso ao mercado de trabalho. Deste modo, a situação é problemática para os licenciados sendo "um problema transversal a todas as áreas". Outro dos pontos críticos que refere prende-se com o facto de se valorizar os meios informais para aceder a um emprego, salientando: "o factor $C$ é muito importante, estou a referir-me à cunha, e acho que tem um peso grande (...). Não estou a dizer que acontece em todo o lado, não acontece. Mas acontece. E é importante". Afirma a injustiça gerada por estes meios, porque "acaba por ser uma selecção feita com pouca transparência, não é? (...)". Mas salvaguarda que "quando nós somos injustiçados por uma situação destas, a primeira coisa que nos ocorre é que se eu conseguisse, obviamente que aproveitava".

A ausência de perspectivas profissionais, ainda que mantendo uma postura de procura activa, é acompanhada por um projecto de prossecução dos estudos num ramo da Sociologia, para além de esperar "que isto venha a melhorar, espero, tenho esperança disso e tento acreditar nisso todos os dias porque se eu acreditar que não, acho que a coisa piora de dia para dia".

Face à situação em que se encontra, afirma que "o futuro é ainda uma coisa incerta", sendo a desejada melhoria da sua situação profissional condicionadora do projecto de vir a "constituir família".

\section{Conclusão}

No presente artigo foram apresentadas as vivências de precariedade no mercado de trabalho de doze licenciadas nas áreas das ciências sociais, humanidades e administração que terminaram os seus cursos entre os anos lectivos de 1996/97 e 2003/04. Dá-se a conhecer, quer os processos objectivos e subjectivos das vivências de precariedade, quer o seu impacto na vida pessoal, familiar, conjugal e social das 
entrevistadas. Com trajectórias precárias assalariadas com múltipla rotatividade e desemprego, Sofia (economista) e Sara (geógrafa), viram a sua inserção no mercado de trabalho dificultada pelo facto de serem mães. O estado civil e a idade também funcionaram como obstáculos. Carolina (licenciada em Gestão) e Antónia (com o curso de Línguas e Literaturas Modernas), são exemplos de trajectórias precárias de trabalhadores independentes com elevada rotação. A forte precariedade que caracteriza as suas trajectórias profissionais tem inviabilizado a concretização de projectos ao nível conjugal e parental, levando ao seu adiamento. Sendo marcada por alguma permanência num mesmo emprego, a precariedade das trajectórias de Elisa (licenciada em Arqueologia) e Catarina (licenciada em Línguas e Literaturas Modernas) é vivenciada de forma distinta. No primeiro caso, ela é impeditiva da concretização de projectos conjugais; no segundo, é facilitadora da organização e supervisão da vida familiar. Ainda que não vivenciem uma situação de desclassificação profissional, a trajectória de investigador-bolseiro é sinónima de ausência de vínculo contratual e, consequentemente, de precariedade. A actividade profissional desempenhada é vivida de forma gratificante, por força da respectiva elevada qualificação do seu conteúdo. Madalena (socióloga) e Susana (psicóloga) não deixam, contudo, de referir o impacto da precariedade na vida conjugal e nos projectos parentais futuros.

Por seu turno, as trajectórias de Mafalda (com o curso de Filosofia) e de Rute (licenciada em História) são pontuadas pelo desemprego e a instabilidade profissional. Este facto inviabiliza, no caso de Mafalda, o projecto de ter mais um filho; e no de Rute de vir a constituir família própria. Para esta última, a idade (39 anos) é vista como mais um obstáculo à inserção na área da sua formação académica. Matilde (licenciada em Línguas e Literaturas Modernas) e Rita (socióloga) nunca transitaram para o mercado de trabalho, permanecendo, presentemente, no desemprego. Embora não se conforme, a exclusão do mercado de trabalho por parte de Matilde fê-la assumir as responsabilidades familiares na totalidade, reproduzindo um modelo assimétrico de papéis de género na família. Rita arrepende-se de ter investido na sua formação em Sociologia e a ausência 
de expectativas ao nível da sua inserção profissional impede-a de concretizar projectos conjugais e parentais.

Os retratos de precariedade apresentados reforçam a importância do conceito de género para a análise das trajectórias profissionais precárias. Aliado à idade, ao estado civil, ao curso e ao facto de se ter filhos, o género funciona como um factor que estrutura a inserção profissional destas mulheres, acentuando as suas trajectórias de precariedade.

A valorização conferida ao diploma escolar, numa fase inicial, acaba por perecer perante as dinâmicas do mercado de trabalho e a actuação dos empregadores, cujas práticas constituem também factores explicativos do agravamento dos processos de precariedade profissional vividos por estas mulheres. Em todas as narrativas é referida a responsabilidade da precariedade no adiamento de projectos pessoais, conjugais, familiares e parentais. 


\section{BIBLIOGRAFÍA}

- Aboim, Sofia (2007): “Clivagens e continuidades de género face aos valores da vida familiar em Portugal e noutros países europeus". In Karin Wall e Lígia Amâncio (orgs.): Família e Género em Portugal. Lisboa: ICS, Cap. 1, pp. 35- 91.

- Amâncio, Lígia (1994): Masculino e Feminino. A Construção Social da Diferença. Porto: Afrontamento.

- Andersen, Margaret L. (1997): Thinking About Woman. Sociological Perspectives on Sex and Gender. Boston: Allyn and Bacon.

- Bourdieu, Pierre (1998): La Domination Masculine. France: Éditions du Seuil.

- Coutrot, Laurence e DUBAR, Claude (dir.) (1992) : Cheminements professionnels et mobilités sociales. Paris: La Documentation Française.

- Crompton, Rosemary (2006): Employment and the family. The reconfiguration of work and family life in contemporary societies. Cambridge: Cambridge University Press.

- Denzin, Norman K. \& LINCOLN, Yvonna S. (1998): Collecting and Interpreting Qualitative Materials. Thousand Oaks: Sage Publications. . (1998): Strategies of Qualitative Inquiry. London: Sage Publications.

- Dias, Isabel (2008): "Violência contra as mulheres no trabalho: O caso do assédio

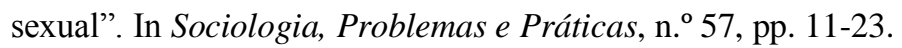

. (2008): "Violência e género em Portugal: Abordagem e intervenção". In Cuestiones de Género: de la igualdad Y la diferencia, n. ${ }^{\circ}$ 3, pp. 153-171. . (2007): "Família e trabalho feminino: O Género das (des)igualdades". In Exequo, n. ${ }^{\circ} 15$, pp. $149-166$.

- Elias, Norbert (1993a) - A Sociedade dos indivíduos. Lisboa: Publicações Dom Quixote. . (1993b): Mozart. Sociologia de um génio. Lisboa: Asa. 
- Gálvez, Natalia Papí; LINARES, Maria José F. (2005): “La conciliación del empleo y del hogar: repuesta y reflejo de una organización del trabajo construida desde la institución del género”. In Reis, n. ${ }^{\circ}$ 110/05, pp. 149-171.

- Gavray, Claire (2006): “Au fur et à mesure qu'elles se construisent, les trajectoires professionnelles divergent entre les sexes: 1'exemple belge". In Formation et Employ, no 93, pp. 49-77.

- Gonçalves. Carlos (coord.) (2009): Licenciados, precariedade e família. Porto: Estratégias Criativas (em publicação).

- Giddens, Anthony (2004): Sociologia. Lisboa: Fundação Calouste Gulbenkian, 4. ${ }^{\text {a }}$ Edição.

- Guionnet, Christine; NEVEU, Erik (2005): Féminins/Masculins. Sociologie du Genre. Paris: Armand Colin.

- Kvale, S. (1996): Inter Views: An introduction to qualitative research interviewing. Thousand Oaks: CA: Sage Publications.

- Núncio, Maria José da Silveira (2008): Mulheres em Dupla Jornada. A Conciliação entre o Trabalho e a Família. Lisboa: Instituto Superior de Ciências Sociais e Políticas.

- Veloso, Luísa (2007): Empresas, identidades e processos de identificação. Porto: Editora da Universidade do Porto. 